\title{
Support for smoke-free vocational education settings: An exploratory survey of staff behaviours, experiences and attitudes
}

\author{
Billie Bonevski, Christine L. Paul, Raoul A. Walsh, Jamie Bryant and Christophe Lecathelinais
}

\section{Introduction}

Exposure to tobacco smoke continues to be one of the most preventable causes of disease and death. ${ }^{1}$ Tobacco control policies and programs have resulted in significant declines in smoking prevalence in most developed countries. ${ }^{2} \mathrm{~A}$ central component to comprehensive tobacco control initiatives is smoke-free legislation. Many countries have legislated smoking restrictions in various public places such as pubs, restaurants and workplaces. ${ }^{3}$ Like in other Australian states, in New South Wales (NSW) the Smoke Free Environment Act 2000 prohibits smoking in enclosed public spaces. However, there still remains room for improvement within some settings, including further education campuses not yet implementing comprehensive smoke-free policies. ${ }^{4,5}$

Technical and Further Education (TAFE) is a highly popular tertiary education option for those who do not wish to attend university but are interested in formal trade or vocational training. In Australia TAFE enrolments outnumber university enrolments five to one, with almost half of the enrolled students aged 15-24 years. ${ }^{6}$ The demographics of TAFE student enrolments suggest that it serves those in a lower socio-economic position ${ }^{6}$ and that many students train in 'blue collar' environments with high smoking prevalence.?
Available Australian data show that smoking prevalence rates among TAFE students tend to be high (47\%) and similar to those found in unemployed youth (42\%). ${ }^{8-10}$ Importantly, self-reported intentions to quit smoking were also high (66\%). Given that tobacco smoking rates are high among the TAFE student population, TAFE may be an important environment in which to apply health-promotion strategies and modify the environment to make it supportive of quitting and not starting smoking.

The application of smoke-free policies in the TAFE setting presents a number of advantages for students and staff. First, the case for restricting smoking in public places was initially made on the basis of strong evidence that such policies protected non-smokers from exposure to second-hand smoke (SHS). ${ }^{11}$ In Australia, indoor workplaces are required by law to be smoke-free. Comprehensive restrictions that also include outdoor areas would reduce exposure to SHS at TAFE, since students tend to spend a good deal of time on campus outdoors. The Surgeon General's report emphasises that there is no safe level of exposure to SHS indoors or outdoors." Second, there is evidence that smoke-free policies also benefit smokers by encouraging reduced consumption, increasing intentions to quit, preventing relapse and improving successful

\section{Abstract}

Issue addressed:TAFE staff are likely to play a pivotal role in achieving smoke-free environments for vocational education. The aim of this survey was to explore staff experiences, behaviours and attitudes towards smoking and smoke-free policies for the TAFE setting.

Method: A web-based survey that measured smoking behaviours, on-campus exposure to smoking, awareness of smoke-free policies and attitudes towards smoking and tobacco control was e-mailed to all staff at one TAFE New South Wales (NSW) institute. In total, 632 staff completed the survey.

Results: Overall, $10 \%$ of staff reported to be current daily, weekly or occasional smokers. Most staff (76.2\%) said that they saw someone smoking at TAFE every day and the most common location was 'outside buildings' (75.3\%). A majority of staff (75.9\%) said they avoided places at TAFE where they were exposed to other peoples' cigarette smoke. Only 26\% said that existing smoking policies were always enforced. Non-smokers had a significantly higher $(p<0.005)$ pro-tobacco control attitudes score mean of 4.2 (SD=1.8), compared with the mean of $2.3(S D=1.4)$ for current smokers. Status as a non-smoker was the only statistically significant predictor of high pro-tobacco control attitude score.

Conclusions: This study provides preliminary evidence that TAFE staff are likely to be supportive of smoke-free TAFE campuses.

Key words: tobacco control, tertiary education settings, attitudes

Health Promotion Journal of Australia 2011;22: 11-16

\section{So what?}

TAFE is an important setting for discouraging smoking uptake and supporting cessation among young adults. This survey reports support for smoke-free TAFE campuses among staff. 
quitting rates. ${ }^{12-14}$ For example, following a smoking ban in workplaces in Ireland, $46 \%$ of smokers reported that they were more likely to consider quitting as a result of the ban, $80 \%$ of quitters indicated that the ban helped them quit and $88 \%$ to remain nonsmoking. ${ }^{14}$

Third, there is some evidence showing that smoking restrictions aid in the prevention or delay of smoking uptake. ${ }^{15,16}$ This is important within the TAFE setting because further education settings may be an important social context for the initiation of smoking, particularly in this age and socio-economic group..$^{17,18}$ The role of teachers and other staff is critical in influencing student smoking behaviour. ${ }^{19,20}$ The enforcement of these policies by staff and teachers both promotes and are a reflection of norms against smoking as an acceptable behaviour. ${ }^{21,22}$ Little progress has been made towards making TAFE sites uniformly and comprehensively smoke-free, despite the successful implementation of several landmark smoke-free policies in Australia and the recent development of a comprehensive guide to tobacco-free university campuses. ${ }^{23}$

Overseas research in colleges and universities suggests that faculty staff are aware of the risks of tobacco products ${ }^{24}$ and that student support for campus tobacco control policies is strong. ${ }^{25}$ However, no information regarding Australian TAFE staff's smoking experiences and tobacco control attitudes exists. This study aimed to measure staff experiences, behaviours and attitudes towards smoking and smoke-free policies for the TAFE setting. A secondary aim was to explore socio-demographic and work-related factors associated with smoking and pro-tobacco control attitudes.

\section{Methods}

\section{Setting}

During the period March to June 2009, a web-based survey was conducted among staff employed at one large institute of TAFE in Sydney. The institute, which received 75,826 student enrolments in 2009, is made up of nine campuses, each specialising in different trades, such as hospitality, electrical and auto mechanics.

All staff were invited to participate via a letter sent to their TAFE e-mail address from the institute manager of human resources using a staff e-mail distribution list. A non-probability sampling frame was used. An attempt was made to collect data from all relevant staff, not a random sample. There were no exclusion criteria. The only eligibility criterion was the necessity for staff to be currently employed at one of the nine TAFE campuses of the participating TAFE NSW institute. There were 19,520 staff in TAFE NSW in 2008, and 3,300 were employed in the surveyed TAFE institute. ${ }^{26}$ The 'subject' of the invitation e-mail stated 'Health and Well-being Survey'. Staff members were asked to click on a link in the e-mail to complete an anonymous web-based survey. Two reminder e-mails approximately one-month apart were sent to all staff. The study was approved by the University of Newcastle's Human Research Ethics Committee.

\section{Measures}

The smoking survey was embedded within the general 48-item 'Health and Well-being Survey' that included items on height and weight, nutrition, physical activity and alcohol use. The survey took approximately 10 minutes to complete. Given no previous survey of this type for TAFE staff was located, the survey was developed using items from similar pen-and-paper surveys used with different target groups. ${ }^{27,28}$ The web-based survey was constructed by a member of the research team (JB) using SurveyMonkey software and reviewed by an expert advisory group of health risk behaviour academics and researchers and the project's TAFE collaborator. Following feedback and modifications, the web survey was pilot tested with a small number of teaching staff $(n=10)$ at one of the institute's campuses to ensure appropriateness, brevity and useability. This paper is concerned with the following items:

1. Previously used ${ }^{28}$ demographic items about age and gender, marital status, income, country of birth and the language spoken at home.

2. Work characteristics, including years worked at TAFE, employment status and position - this was developed by the research group specifically for this survey.

3. Current and previous smoking status (daily, weekly, less than weekly or non-smoker). Current smokers were defined in this study as those who reported smoking daily, weekly or occasionally. For smokers, age of uptake, number of cigarettes smoked per day, quit attempts, and preferences for type of help or support to quit were measured. The smoking status questions have been endorsed by an expert group and have demonstrated validity and reliability. ${ }^{29}$ Quitting items were derived from the California Tobacco Survey. ${ }^{30}$

4. Experiences with smoking/smokers at TAFE (frequency and locations of seeing people smoke at TAFE, and avoidance of known smokers areas). These items were developed specifically for this survey based on relevant literature.-11

5. Attitudes towards smoking and restrictions at TAFE or affiliated work sites were developed based on related literature. ${ }^{9-11}$ The response format involved five-point Likert-type scales (strongly agree, agree, neither agree or disagree, disagree, strongly disagree) and a'don't know' option.

\section{Analysis}

All analyses were conducted using SAS 9.0 statistical software.

\section{Demographic, work and smoking-related behaviour and experiences}

These items are reported using proportions and 95\% confidence intervals $(95 \% \mathrm{Cl})$. The relationship between various demographic and work variables (age, gender, marital status, country of birth, language, years at TAFE, role and status) and smoking status (current smoker versus non-smoker) was initially assessed using Chi square $\left(\chi^{2}\right)$ analyses. Predictor variables that were statistically significantly associated with smoking status at the 0.25 significance level were entered into a backward logistic regression procedure. Odds ratios and 95\% confidence intervals were calculated for the predictor variables entered into the multivariate logistic regression.

\section{Staff attitudes and pro-tobacco control attitude score}

Staff attitudes towards smoking and smokers on campus and in workplaces have been reported for each of the seven items using 
percentages and 95\% confidence intervals. For reader ease,'strongly agree' and 'agree' were collapsed into a single category and'strongly disagree' and 'disagree' were collapsed into a single category for each item. The results for current smokers and non-smokers have been reported separately and compared using $\chi^{2}$ analyses. In addition to the reporting of individual attitude items, an aggregated score was calculated to represent views that were supportive of tobacco control or negative towards smokers using the seven items by allocating a score of 1 to responses reflecting agreement with tobacco control positive statements and 0 to those indicating a view that was less supportive. In this way, the maximum tobacco control positive score is 7. Means and standard deviations (SD) of tobacco control positive scores for smokers and non-smokers have been presented and compared using a two-sample t-test. Following examination of the distribution of scores, a cut-off for'high'tobacco control positive score was set at 6 or more. A logistic regression was conducted to examine factors that predicted high tobacco control attitudes (scores of 6 or 7). Odds ratios and 95\% confidence intervals were calculated for the predictor variables entered into the logistic regression. The goodness of fit of the logistic regression models were assessed using the Hosmer-and-Lemeshow test.

\section{Results}

\section{Sample}

Of the 3,330 staff sent the invitation via e-mail, 832 (25\%) staff members opened the e-mail. Of these, 632 completed the survey (response rate of 19\%). Table 1 shows the demographic and workrelated characteristics of the sample. Table 1 also shows the age and gender distribution of the entire institute staff population.

\section{Respondent smoking behaviours}

Table 1 shows the smoking status of participants. Only 10\% (7.4\%$12.4 \%)$ of the sample reported to be a current daily $(8.1 \%)$ or occasional (1.8\%) smokers. Approximately one quarter of the sample $(25 \%, 21.4 \%-28.6 \%)$ reported to have been daily smokers in the past and one third (30\%, 26.2\%-33.8\%) reported to have smoked at least 100 cigarettes in their life.

Of the current smokers $(n=59), 48 \%$ (35.1\%-60.9\%) reported smoking up to 10 cigarettes per day and 52\% (39.1\%-64.9\%) reported smoking more than that amount. The majority $(75 \%, 63.9 \%-86.1 \%)$ of smokers reported to have been daily smokers before commencing working at TAFE. The mean age when respondents reported they began regular smoking was 19 years (median 17).

Most smokers (39\%, 26.5\%-51.6\%) reported no or up to two attempts to quit smoking for a day or longer over the previous 12 months. A majority (64\%, 51.6-76.4\%) reported to have remained abstinent for at less than four weeks during their most recent quit attempt.

Smoking was more prevalent among those born in Australia (11.7\% v 6.1\%, $\chi^{2}=4.4, d f=1, p=0.04$ ), who had worked fewer years (fewer than four) at TAFE $\left(18.2 \% \vee 8.4 \%, \chi^{2}=8.0, \mathrm{df}=1, p=0.005\right)$ and were in administrative (rather than teaching or managerial) roles (16\% v 7.4\%, $\left.\chi^{2}=8.8, d f=2, p=0.01\right)$. The backward stepwise logistic regression resulted in country of birth and position at TAFE as being statistically
Table 1: Sample demographics and work characteristics with age and gender comparison for all staff human resources data.

\begin{tabular}{|c|c|c|c|}
\hline & $\mathrm{N}^{*}$ & $\begin{array}{c}\text { Sample } \\
(n=632) \\
\%(95 \% C l)\end{array}$ & $\begin{array}{c}\text { All institute } \\
\text { staff }^{\dagger}(n=3,300) \\
\%(95 \% C l)\end{array}$ \\
\hline \multicolumn{4}{|l|}{ Age } \\
\hline$<29$ years & 22 & $3.5(2.1-5.0)$ & $4.9(4.2-5.6)$ \\
\hline $30-39$ & 80 & $12.8(10.1-15.4)$ & $16.8(15.5-18.1)$ \\
\hline $40-49$ & 177 & $28.2(24.7-31.8)$ & $27.7(26.2-29.2)$ \\
\hline $50+$ years & 348 & $55.5(51.6-59.4)$ & $50.6(48.9-52.3)$ \\
\hline \multicolumn{4}{|l|}{ Gender } \\
\hline Female & 382 & $64.2(60.3-68.1)$ & $58.4(56.7-60.1)$ \\
\hline Male & 213 & $35.8(31.9-39.7)$ & $41.6(39.9-43.3)$ \\
\hline \multicolumn{4}{|l|}{ Country of birth } \\
\hline Australia & 412 & $67.8(64.0-71.5)$ & N/A \\
\hline Other & 196 & $32.2(28.5-36.0)$ & \\
\hline \multicolumn{4}{|l|}{ Language } \\
\hline English & 541 & $89.0(86.5-91.5)$ & N/A \\
\hline Other & 67 & $11.0(8.5-13.5)$ & \\
\hline \multicolumn{4}{|l|}{ Marital status } \\
\hline Married/de-facto & 491 & $78.2(74.9-81.4)$ & N/A \\
\hline Divorced/separated & 69 & $11.0(8.5-13.4)$ & \\
\hline Widowed & 12 & $1.9(0.8-3.0)$ & \\
\hline Never married & 56 & $8.9(6.7-11.2)$ & \\
\hline \multicolumn{4}{|c|}{ Household weekly income (gross) } \\
\hline$<\$ 600$ & 40 & $6.8(4.7-8.8)$ & N/A \\
\hline$\$ 601-800$ & 28 & $4.7(3.0-6.4)$ & \\
\hline$\$ 801-1000$ & 71 & $12.0(9.4-14.6)$ & \\
\hline$\$ 1001-2000$ & 252 & $42.6(38.6-46.6)$ & \\
\hline$>\$ 2001$ & 151 & $25.5(22.0-29.0)$ & \\
\hline Don't know & 50 & $8.4(6.2-10.7)$ & \\
\hline \multicolumn{4}{|l|}{ Years worked at TAFE } \\
\hline Less than 2 & 45 & $7.1(5.1-9.1)$ & N/A \\
\hline $2-4$ & 56 & $8.9(6.6-11.1)$ & \\
\hline $5-7$ & 78 & $12.3(9.8-14.9)$ & \\
\hline More than 7 & 453 & $71.7(68.2-75.2)$ & \\
\hline \multicolumn{4}{|l|}{ Employment status } \\
\hline Permanent full-time & 408 & $64.7(60.9-68.4)$ & N/A \\
\hline Permanent part-time & 49 & $7.8(5.7-9.9)$ & \\
\hline Other (casual/agency) & 174 & $27.6(24.1-31.1)$ & \\
\hline \multicolumn{4}{|l|}{ Role at TAFE } \\
\hline Teaching & 324 & $52.1(48.2-56.0)$ & N/A \\
\hline Management & 75 & $12.1(9.5-14.6)$ & \\
\hline Administration & 142 & $22.8(19.5-26.1)$ & \\
\hline Other & 81 & $(10.4-15.7)$ & \\
\hline \multicolumn{4}{|l|}{ Current smoking status } \\
\hline Daily & 46 & $8.1(5.9-10.4)$ & N/A \\
\hline At least once a week & 2 & $0.4(0.0-0.8)$ & \\
\hline Less than once a week & 8 & $1.4(0.4-2.4)$ & \\
\hline No not at all & 509 & $90.1(87.6-92.6)$ & \\
\hline
\end{tabular}

* Not all columns add to 632 due to missing values.

tData obtained from the TAFE human resources department. 
significant predictors of smoking status. The odds ratio for current smoking was 2.1 (1.1-4.2) among those born in Australia $(p=0.04)$ compared with respondents born overseas and 2.5 (1.3-4.9) among those with administrative positions ( $p=0.007$ ) compared with those in teaching positions.

\section{Exposure to tobacco smoke at TAFE campuses and worksites}

Most respondents (76.2\%, 72.7\%-79.8\%) said that they saw someone smoking at TAFE every day with only $4.5 \%$ (2.8\%-6.2\%) saying they rarely or never saw people smoking at TAFE. The most common locations at which respondents said they saw people at TAFE smoking were 'outside buildings' (75.3\%, 71.7\%-78.9\%), 'designated smoking areas' (62.7\%, 58.7\%-66.7\%), 'at outdoor eating areas' (48.1\%, 43.9\%-52.3\%), 'in the car park' (46.7\%, 42.5\%-50.8\%), 'outside the entrance to TAFE' (29.7\%, 25.9\%-33.5\%). More than 14\% of respondents said they saw people smoking 'everywhere' (14.2\%, $11.3 \%-17.2 \%)$

A majority of respondents $(75.9 \%, 72.3 \%-79.5 \%)$ said they avoided places at TAFE where they were exposed to other peoples' cigarette smoke.

Thirty-four per cent of the sample $(n=187)$ said they attended off-site workplaces as part of their teaching activities. Of these, approximately two thirds $(65.2 \%, 58.4 \%-72.1 \%)$ said that most or some people smoke at those worksites.

\section{Awareness of current TAFE smoke-free policy}

When asked about written rules or policies related to smoking at their TAFE, 30.0\% (26.4\%-33.6\%) said smoking was only allowed outdoors, 55.8\% (51.9\%-59.7\%) said smoking was only allowed in certain areas, $4.2 \%$ (2.6\%-5.8\%) said smoking was not allowed anywhere indoors or outdoors at TAFE, $4.0 \%$ (2.6\%-5.8\%) said that no policy existed and $6.1 \%$ (4.2\%-8.0\%) said they did not know whether a policy existed.

When asked how often these rules or policies were enforced, 11\% (8.6\%-13.5\%) said 'never', 63.1\% (59.3\%-66.9\%) said 'sometimes' or 'most of the time' and $25.8 \%$ (22.4\%-29.2\%) said 'always'.

\section{Attitudes towards smoking and smoke-free at TAFE}

Table 2 shows the results of the attitude items by smoking status and for the overall respondent sample. Differences according to smoking status are evident on a number of the attitude statements. For example, although 73\% (68.8\%-76.7\%) of non-smokers would like the whole TAFE site to be smoke-free, only 13\% (4.0\%-21.9\%) of current smokers agreed. Also, more non-smoking TAFE respondents (42\%, $37.6 \%-46.4 \%$ ) felt it was part of their responsibility to be non-smoking role models for students than current smokers (13\%, 4.0\%-21.9\%).

Overall, the mean tobacco control attitude score was 3.55 (SD=2.1, median=4), however non-smokers had a significantly higher mean of $4.2(\mathrm{SD}=1.8)$, compared with the mean of $2.3(\mathrm{SD}=1.4)$ for current smokers.

A backward stepwise logistic regression was conducted to examine factors associated with a high tobacco control score based on those that were significant at the 0.25 level from the bivariate models (gender, country of birth and smoking status). Smoking status was the only statistically significant ( $p=0.005$ ) predictor of high tobacco control positive scores. The odds ratio for high tobacco control attitudes was 16.9 (2.3-123.8) among non-smokers compared with smokers.

\section{Discussion}

The results of this study need to be considered within the context of its methodological limitations. Foremost, the study's response rate was low. Low response rates throw into question the representativeness of the sample, as response bias may have occurred. In order to examine the representativeness of our sample, we compared the age and gender of our sample with that of the entire institute staff. Given the age and gender distribution of the study sample was similar to the population from which it was drawn this suggests that the responders adequately represented staff at this TAFE NSW institute (Table 1). However, the survey was restricted to staff who had ready and regular access to theirTAFE e-mail account. Of the 3,300 staff employed by the surveyed TAFE institute, only 832 accessed their e-mail accounts during the life of the survey. It should be noted that a high proportion of TAFE staff are employed

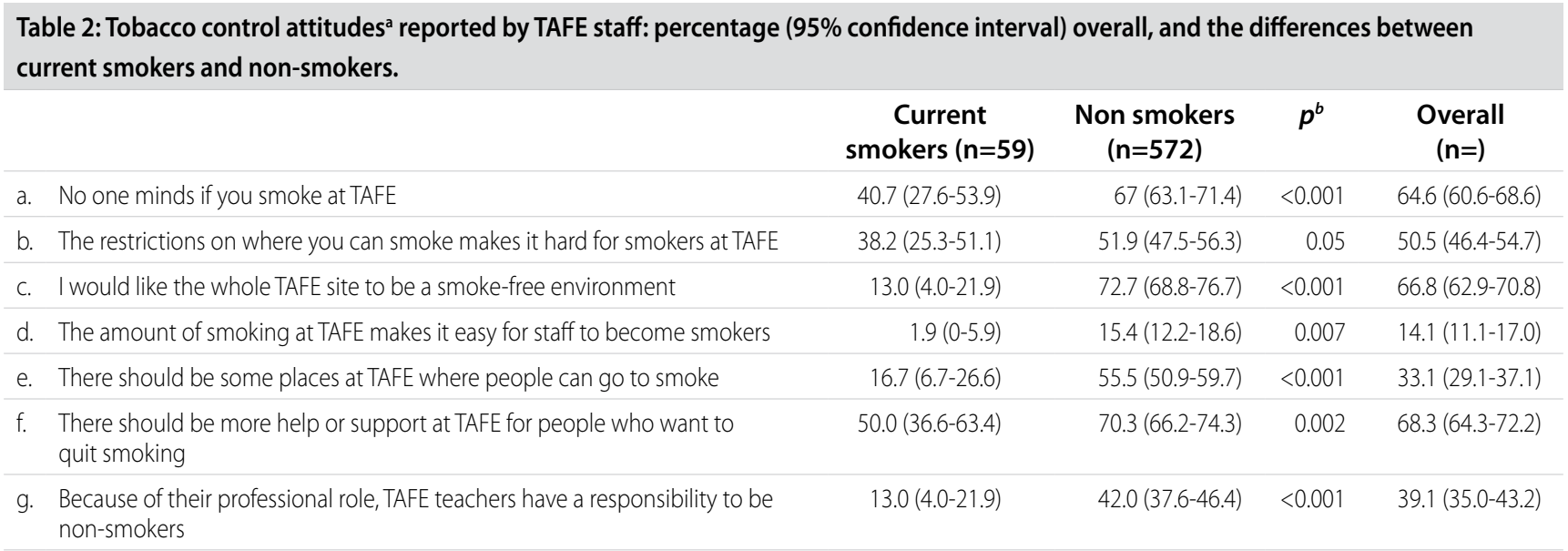

a. Tobacco control supportive attitude was strongly agree/agree with statements (), d), f), g) and strongly disagree/disagree with statements a), b), e). b. Results of Chi square tests. 
on short-term and casual contracts and that these people are less likely to regularly check their TAFE e-mail accounts and so would be under-represented in this sample. The subject heading of the invitation e-mail sent to all staff was a generalised one that should have minimised selection bias by a sample interested in smoking topics. The low response rate we found here is similar to other studies using e-mailed surveys. ${ }^{31}$ Access to e-mail and ways to increase low response to e-mailed surveys are important areas in need of further methodological examination.

Another limitation of this study was the reliance on self-reported data. This could have influenced estimates of smoking and quitting behaviours, as some respondents may have provided socially desirable responses. Although respondent anonymity should have substantially reduced the bias, ${ }^{32}$ we acknowledge that selfreported smoking may have been underestimated. Due to the small proportion of respondents reporting being current smokers (10\%), the size of the smoker sub-sample was very small and may have affected some analyses. Finally, the generalisability of the survey results was limited because the survey was restricted to a single TAFE institute. However, the institute is one of the largest in NSW and staff from all campuses were included. Further surveys of TAFE staff from other institutes would contribute to the generalisability of the current results.

Notwithstanding these limitations, this preliminary survey provides some of the first Australian data about TAFE staff smoking at TAFE campuses and their knowledge and attitudes towards smoke-free policy at TAFE. The patterns of self-reported smoking status among TAFE staff in the current survey (10\% with $25-30 \%$ ex-smokers) were slightly lower than recent NSW community smoking surveys, which found current smoking among adults to be $14 \%$, with $30 \%$ reporting to be ex-smokers. ${ }^{33-34}$ The results were similar to other research that found lower than population level smoking rates among teachers ${ }^{20}$ and university faculty. ${ }^{24}$ There were significant differences in smoking rates between the higher SES/professional positions such as teachers and managers (8\%) and the more bluecollar positions such as administration and 'other', which included general staff such as security, catering and cleaners (15\%). This socioeconomic gradient in smoking rates closely mirrored that of the general NSW population, where smoking in the more advantaged quintile of socio-economic status was half (13\%) that of the least advantaged quintile (26\%). ${ }^{35}$ TAFE may be a suitable setting for workplace health programs to address smoking among its staff from lower SES backgrounds.

Respondents reported frequently seeing people smoke at various locations around TAFE. Many of these smokers were likely to be students. Close to a third of respondents said that they saw people smoking near the entrance to TAFE. Most TAFE respondents in the current survey said they avoided those locations where they would be exposed to other people's smoke. The evidence regarding the harms of SHS is strong. ${ }^{11}$ In a large review of the literature, Hopkins et al. (2001) concluded that, generally, reductions in ETS exposure were greater in workplaces that had smoking bans than in those with only smoking restrictions. ${ }^{36}$ Smoking bans not only protect non-smokers from the dangers of ETS, they also encourage smokers to quit or reduce consumption. ${ }^{12-14}$ Within the TAFE context they may have the added benefit of delaying initiation of smoking or the advance from experimental to established smoker among students. ${ }^{15}$ In the current survey, most respondents (51\%) recognised that the existing restrictions on smoking at TAFE were not making it harder to smoke and most respondents (67\%) wanted a total ban on smoking at the TAFE site. These results were similar to surveys of other workplaces that found that workplace smoking bans were acceptable. ${ }^{37}$

Other research has highlighted the importance of enforcement, particularly in relation to school-based policies and young people's smoking behaviours. ${ }^{19-22}$ While most respondents (56\%) were aware that smoking was only allowed 'in certain areas', only 30\% accurately identified 'outdoor areas only' and a small proportion of respondents (14\%) had inaccurate recollections of the smoking policy or were not aware of a policy. More effective signage around campus would help staff and students identify smoke-free areas. Only 26\% of respondents said that existing smoke-free policies were always enforced. At the time of this survey, staff at the surveyed TAFE institute were guided by the Department of Education and Training (DET) Code of Conduct (2004) policy for tobacco which states in its entirety that, "Staff must not smoke or permit smoking in any DET building, enclosed area or on any school grounds. In the case of cross-sectoral sites, a decision regarding the extent of 'school grounds' will need to be made in the local context (Refer Smoke Free Environment Act 2000). Care should also be taken to ensure that tobacco smoke does not enter DET buildings".38 The lack of a definition of 'school grounds' and guidance as to how to enforce this policy is probably impeding its effective enforcement. It may be important to define the role of staff, including casual and part-time staff, in enforcing smoke-free policies. It may be useful for TAFE to model the development of its smoke-free policies on the university campus Guide for a tobacco-free campus produced recently by the Action on Smoking and Health Australia group. ${ }^{23}$ This three-step guide offers not only detailed information on how to develop a tobacco-free campus policy (step 1), but also includes pragmatic advice about effective ways to implement (step 2), and support, monitor and evaluate the policy (step 3).

Generally, respondents expressed negative attitudes towards smoking and were largely supportive of tobacco control. Most noticeably, $68 \%$ of respondents overall agreed that there should be more help or support at TAFE for people who wanted to quit smoking, with $50 \%$ of smokers also agreeing. While $67 \%$ of the overall sample indicated that they would like the whole TAFE site to be a smoke-free environment, a much higher proportion of non-smokers were in agreement with total smoking bans (73\%) than current smokers (13\%). Not surprisingly, more non-smokers expressed high tobacco control supportive attitudes than smokers. Given that selfreported smoking rates were low, most respondents were receptive to total smoke-free policies on campus. The results were similar to those of community surveys that have repeatedly found negative attitudes towards smoking and positive responses to tobacco control efforts ${ }^{33-34}$ and workplace-specific surveys that have found high levels of acceptability towards smoke-free environments. ${ }^{33,37,39}$

In conclusion, the results suggest that total smoke-free policies within the TAFE setting are likely to be readily accepted by staff. 
Although there were conflicting reports on what respondents believed was contained within the current smoke-free policies, few respondents reported to be smokers, facilitating a positive nonsmoker social norm within the TAFE environment. Many respondents reported that they avoided places within TAFE where they knew they would be exposed to other people's tobacco smoke and most respondents had positive attitudes towards a smoke-free TAFE. The survey identified a setting that requires further investigation as a potential place for implementing no smoking policies.

\section{Acknowledgement}

The study was conducted by the University of Newcastle and Cancer Council New South Wales' Centre for Health Research \& Psychooncology (CHeRP), with infrastructure support from the Hunter Medical Research Institute. The views expressed are not necessarily those of the Cancer Council. Our gratitude is extended to the study participants and our collaborators at TAFE NSW, particularly Ms Catherine Melville and Mr Paul Perkins.

\section{Funding}

The work was supported by the Cancer Council New South Wales.

\section{References}

1. Scollo MM, Winstanley MH, editors. Tobacco in Australia: Facts and Issues. 3rd ed. Melbourne (AUST): Cancer Council Victoria; 2008.

2. Hopkins DP, Briss PA, Ricard CJ, Husten CG, Carande-Kulis VG, Fielding JE, et al. Reviews of evidence regarding interventions to reduce tobacco use and exposure to environmental tobacco smoke. Am J Prev Med. 2001;20 Suppl 2:16-66.

3. Levy DT, Chaloupka F, Gitchell J. The effects of tobacco control policies on smoking rates: a tobacco control scorecard. J Public Health Manag Pract. 2004;10:338-53.

4. National Preventative Health Taskforce. Australia: The Healthiest Country by $2020-$ National Preventative Health Strategy - The Roadmap for Action. Canberra (AUST): Commonwealth of Australia: 2009. Publications No:P3 - 5444.

5. Action on Smoking and Health Australia. Australian Universities Tobacco Policies Survey [survey on the Internet]. Sydney (AUST): ASH Australia; 2007 [cited 2010 May 5]. Available from: www.ashaust.org.au/lv4/unisurvey07.doc

6. Department of Education and Training. TAFE NSW Performance Highlights. Sydney (AUST): State Government of New South Wales; 2006.

7. Barbeau EM, Calderon P, Hartman C, Quinn M, Markkanen P, et al. Results of a unionbased smoking cessation intervention for apprentice iron workers (United States). Cancer Causes Control 2006:17:53-61.

8. Edwards D, Wakefield M, Roberts L, Owen N. Smoking behaviour, stage of change and preferences for cessation assistance among young people attending an institute of Technical and Further Education (TAFE). Health Promot J Austr. 1997:7:18-21.

9. Stanton WR, Lowe JB, Fisher J, Gillespie AM, Rose JM. Beliefs about smoking cessation among out-of-school youth. Drug Alcohol Depend. 1999;54(3):251-8.

10. Fisher JK, Stanton WR, Lowe JB. Healthy behaviours, lifestyle, and reasons for quitting smoking among out-of-school youth. J Adolesc Health. 1999;25(4):290-7.

11. Office of Surgeon General. The Health Consequences of Involuntary Exposure to Tobacco Smoke [A Report of the Surgeon General]. Rockville (MD): US Department of Health and Human Services; 2006

12. Farkas A, Gilpin E, Distefan J, et al, The effects of household and workplace smoking restrictions on quiting behaviours. Tob Control. 1999;8:261-5.

13. Biener L, Nyman A. Effects of workplace smoking policies on smoking cessation: results of a longitudinal study. Occup Environ Med. 1999:41:1121-7.

14. Fong GT, Hyland A, Borland R, Hammond D, Hastings G, McNiell A, et al. Reductions in tobacco smoke pollution and increases in support for smoke-free public places following the implementation of comprehensive smoke-free workplaces legislation in the Republic of Ireland. Findings from the ITC Ireland/UK survey. Tob Control. 2006:15 Suppl 3:51-8.

15. Wakefield M, Chaloupka F, Kaufman N, et al. Effect of restrictions on smoking at home, at school, and in public places on teenage smoking: cross section survey. BMJ. 2000;321:333-7.

16. Farkas $A$, Gilpin $E$, White $M$, et al. Association between household and workplace smoking restrictions and adolescent smoking. JAMA. 2000;284:717-22.

17. Pierce JP, Naquin M, Gilpin E, Giovino G, Mills S, Marcus S. Smoking initiation in the United States: a role for workplace and college smoking bans. J Nat C Cancer Inst. 1991:83(14):1009-13.

18. Wechsler H, Rigotti NA, Gledhill-Hoyt H, Lee H. Increased levels of cigarette use among college students: A cause for national concern. JAMA. 1998:280:1673-8.
19. Poulsen LH, Osler M, Roberts C, Due P, Damsgaard MT, Holstein BE. Exposure to teachers smoking and adolescent smoking behaviour: analysis of cross sectional data from Denmark. Tob Control. 2002:11:246-51.

20. Charlton A. Teachers'smoking habits. J Public Health (Oxf). 1984;6(4):273-80

21. Lipperman-Kreda S, Grube JW. Students' perception of community disapproval, perceived enforcement of school antismoking policies, personal beliefs, and their cigarette smoking behaviours: results from a structural equation modelling analysis. Nicotine Tob Res. 2009;11(5):531-9.

22. Turner KM, Gordon J. Butt in, butt out: pupils' views on the extent to which staff could and should enforce smoking restrictions. Health Educ Res. 2004;19(1):40-50.

23. Action on Smoking and Health Australia. Guide for a Tobacco-free Campus. Sydney (AUST): ASH Australia; 2009.

24. Peiper N, Stone R, van Zyl R, Rodu B. University faculty perceptions of the health risks related to cigarettes and smokeless tobacco. Drug Alcohol Rev. 2010;29:121-30.

25. Rigotti NA, Regan S, Moran SE, Weschler H. Students' opinion of tobacco control policies recommended for US colleges: a national survey. Tob Control. 2003;12:251-6.

26. National Centre for Vocational Education Research. Vocational Education and Training Workforce Data 2008: A Compendium. Canberra (AUST): Commonwealth Department of Education, Employment and Workplace Relations; 2010.

27. Walsh R, Cholowski K, Tzelepis F, Stojanovski E. Nursing and teaching students: smoking prevalence, attitudes and confidence about tobacco control roles. Unpublished observations.

28. Walsh RA, Tzelepis F, Paul CL, McKenzie J. Environmental tobacco smoke in homes, motor vehicles and licensed premises: community attitudes and practices. Aust $N$ ZJ Public Health. 2002;26:536-42.

29. Health Data Standards Committee 2008. National Health Data Dictionary. Ver 14 Canberra (AUST): Australian Institute of Health and Welfare, 2008. Catalogue No.: HWI 101

30. Farkas AJ, Pierce JP. Zhu S-H, Rosbrook B, Gilpin EA, Berry C, et al. Addiction versus stage of change models in predicting smoking cessation. Addiction. 1996;91:1271-80.

31. Sheehan K. Email survey response rates: A review. Journal of Computer-mediated Communication [serial on the Internet]. 2001 [cited 2010 Mar 10];6(2)January. Available from: http://jcmc.indiana.edu/vol6/issue2/sheehan.html

32. Adams J, Parkinson L, Sanson-Fisher RW, Walsh RA. Enhancing self-report of adolescent smoking: The effects of bogus pipeline and anonymity. Addict Behav. 2008;33:1291-6.

33. Walsh RA, Paul CL, Tzelepis F, Stojanovski E, Tang A. Is government action out-of-step with public opinion on tobacco control? Results of a New South Wales population survey. Aust N ZJ Public Health. 2008;32:482-8.

34. Bonevski B, Walsh R, Paul C. Government slow to act on public preference on total pub smoking ban. Aust N Z J Public Health. 2009;33(1):95.

35. White $V$, et al. How has the prevalence of cigarette smoking changed among Australian adults? Trends in smoking prevalence between 1980 and 2001. Tob Control 2003:12:ii67-ii74.

36. Hopkins DP, Briss PA, Ricard CJ, Husten CG, et al. Reviews of evidence regarding interventions to reduce tobacco use and exposure to environmental tobacco smoke. Am J Prev Med. 2001:20 Suppl 2:16-66.

37. Hocking B, Borland R, Owen N, Kemp G. A total ban on workplace smoking is acceptable and effective. Journal of Occupational Medicine. 1991;33(2):163-7.

38. TAFE NSW. TAFE NSW Gazette. 2001;1(31).

39. Wakefield M, Cameron M, Murphy M. Potential for smoke-free policies in social venues to prevent smoking uptake and reduce relapse: a qualitative study. Health Promot Pract. 2009;10(1):119-27.

\section{Authors}

Billie Bonevski, The Centre for Health Research \& Psycho-oncology (CHeRP), The Cancer Council New South Wales and the University of Newcastle.

Christine L Paul, Priority Research Centre for Health Behaviour, School of Medicine \& Public Health, University of Newcastle, NSW.

Raoul A Walsh, Jamie Bryant and Christophe Lecathelinais, The Centre for Health Research \& Psycho-oncology (CHeRP), The Cancer Council New South Wales and the University of Newcastle.

\section{Correspondence}

Dr Billie Bonevski, Centre for Health Research \& Psycho-oncology (CHeRP), David Maddison Building, Level 2, Room 230A, University of Newcastle, Callaghan, NSW 2308;

e-mail:billie.bonevski@newcastle.edu.au 
Copyright of Health Promotion Journal of Australia is the property of Copyright Agency Limited and its content may not be copied or emailed to multiple sites or posted to a listserv without the copyright holder's express written permission. However, users may print, download, or email articles for individual use. 